\title{
EMPHASISING THE USEFULNESS OF SIMULATIONS IN AUDIT EDUCATION: STUDENT PERCEPTIONS AT A SAICA-ACCREDITED SOUTH AFRICAN UNIVERSITY
}

\author{
Rikus de Villliers* \\ North-West University
}

Received: June 2015

Accepted: November 2015

\begin{abstract}
The use of active learning tools such as simulations in accounting education are increasingly stressed by accounting educationalists locally and abroad. This study highlights the benefits of using simulations and how their challenges can be mitigated. The objective was to obtain students' views on the use of simulations in the field of auditing. A qualitative approach in collecting the data was followed, including focus group discussions with third-year audit students at a SAICA-accredited South African university. The results form part of a bigger project involving the development of a simulation instrument for purposes of audit education. The qualitative results showed that the use of simulations in specifically audit education is invaluable to the learning process. The recommendations made on the basis of the content analysis also hold value for lecturers in the wider accounting pedagogy. Areas for further research and development are outlined, and the study's limitations are acknowledged.
\end{abstract}

Keywords

Accounting education; audit lecturer; simulation; South African Institute of Chartered Accountants (SAICA); audit student

*Dr RR de Villiers is a senior lecturer in the School of Accounting Sciences, North-West University, Potchefstroom campus, South Africa [rikus.devilliers@nwu.ac.za]. 


\section{INTRODUCTION}

The most prominent domain in which accounting education research has been performed involves the usefulness of simulations or similar instruments as educational tools in these classrooms. Gurau, Loukis, Ranchhod and Trivedi (2013:76) stated that the use of simulations embodies a vital revolution in education as it provides a useful pedagogical instrument for active, experiential and problem-based learning. This is supported by extensive research which has been conducted on accounting education in the twentieth century (e.g. Fouché, 2006; Fowler, 2005; Mensching, Adams, Gardiner \& Jones, 2012; Nitkin, 2011; Steenkamp \& Rudman, 2007; Steenkamp \& Von Wielligh, 2011).

The study by Mensching et al. (2012) involved a simplified business environment simulation. This simulation was designed to assist students in grasping problematic models of business planning and the development of budgeted financial statements (Mensching et al., 2012:53). The main objective was to create a resilient understanding of the interconnections between various business processes as well as to expose students to business modelling by means of simulations (Mensching et al., 2012:53).

Steenkamp and Rudman (2007) developed a simple simulation that assessed the usefulness of simulation use to students at undergraduate level. This study was followed up in subsequent years by Steenkamp and Von Wielligh (2011) who examined the perceptions of the same group of students who completed the simulation at undergraduate level, but with improved comprehension, as they had in the meantime completed another year of postgraduate education as well as a minimum of six months of traineeship in public practice. Other success stories in the use of simulations are those of Fouché (2006) and Fowler (2005), who developed an accounting simulation to enhance students' understanding of the accounting process all the way from transaction initiation to financial statement compilation.

The results of these studies, among others noted later, have shown that the use of simulations contributes to learning in a variety of ways by introducing students to the 'reality' of what is being studied in a textual format. The present study gives an overview of the usefulness of simulations in audit education specifically. This is done by firstly looking into literature on existing uses and usefulness of simulations in accounting education and audit education in particular, followed by statements of the study's objectives and intended value. Next, the research design and results of the qualitative data analysis are provided. A conclusion is formed on the worth of simulations, together with some recommendations based on the findings of the study, which may be beneficial for all lecturers in the accounting pedagogy.

\section{THE USEFULNESS OF SIMULATIONS: AN OVERVIEW}

According to DeCoster and Prater (1973:137), simulations have three distinct advantages for student learning, the first being that they create a positive attitude towards learning and inspire engagement in the learning process. Secondly, active participation encourages learning whereas, thirdly, simulations provide opportunities for integration and application learning (DeCoster \& Prater, 1973:137). Knechel (1989:411-419) stated that an element of business reality is brought to the classroom when using simulations as an active learning tool. He further pointed out that simulations reduce issues of slacking that are caused by traditional teaching methods. Hoffjan (2005:63) and Knechel (1989:411-419) suggested that simulations also provide soft-skill 
practice including team work, collaboration and interpersonal social skills. Hoffjan (2005:63) further argued that:

\begin{abstract}
... business games stimulate students and motivate them to participate to a greater degree than in a conventional classroom situation. Furthermore, business games increase the ability to recall factual knowledge and appear to improve problem-solving skills. Contrary to conventional teacher centered teaching (passive approach) the business game participant is actively engaged in the learning process, which enhances learning effectiveness.
\end{abstract}

However, simulations as active learning tools are also fraught with difficulties and challenges. Fouché and Visser (2008:599), together with Hoffjan (2005:70), noted that time constraints in performing a simulation proved to be the greatest difficulty faced by the majority of students participating in a simulation. They furthermore explained the necessity of clear instructions and facilitation before the simulation is performed to counteract any possible student confusion about what is expected (Fouché \& Visser, 2008:599; Hoffjan, 2005:70).

Giroux and Pasin (2011:1246) identified the same time constraint problem in their study of a simulation on operations management education. They also found that students became frustrated with technical difficulties inherent in the simulation and that educators struggled to provide feedback and answer questions in cases where the simulation took place outside of class time (Giroux \& Pasin, 2011:1246). This yet again confirms the importance of clear instructions and facilitation, as stated by Fouché and Visser (2008:599), before the simulation is performed, to limit any possible confusion, frustration and unanswered questions that students may have while performing the simulation. That being said, all of these studies acknowledge that the advantages for students' learning experience in accounting education exceed the limitations as the ultimate conclusions and feedback from participants were positive and reiterated that the simulations added value to their understanding of the subject. TABLE 1 summarises some of the advantages and challenges that the use of simulations may bring to the classroom, as noted from the literature cited in this study.

\title{
3. OBJECTIVES AND VALUE
}

The literature on the use of different teaching methodologies in accounting education (e.g. Bagley \& Harp, 2012; Botha, 2014; Miller \& Savage, 2009; Steenkamp \& Rudman, 2007) placed focus on obtaining students' perceptions on the usefulness of these methods and the effect these have on student learning predominantly via applying quantitative research methodologies. The objective of the present study was therefore to obtain students' views on the usefulness of simulations in auditing as a subject by following a qualitative approach in collecting the data from students.

This study forms part of a larger project in which an instrument, i.e. audit simulation, was developed to offer students the opportunity to develop the various competencies related to auditing and assurance as well as generic and pervasive skills, as stipulated in the competency framework of the South African Institute of Chartered Accountants (SAICA). In this larger project, where more than one SAICA-accredited university were involved, a mixed methodology was adopted in evaluating this newly developed simulation, with the quantitative findings concluding that that the newly developed audit simulation enhanced students' perceived broad competence significantly. 
TABLE 1: Advantages and challenges of simulations

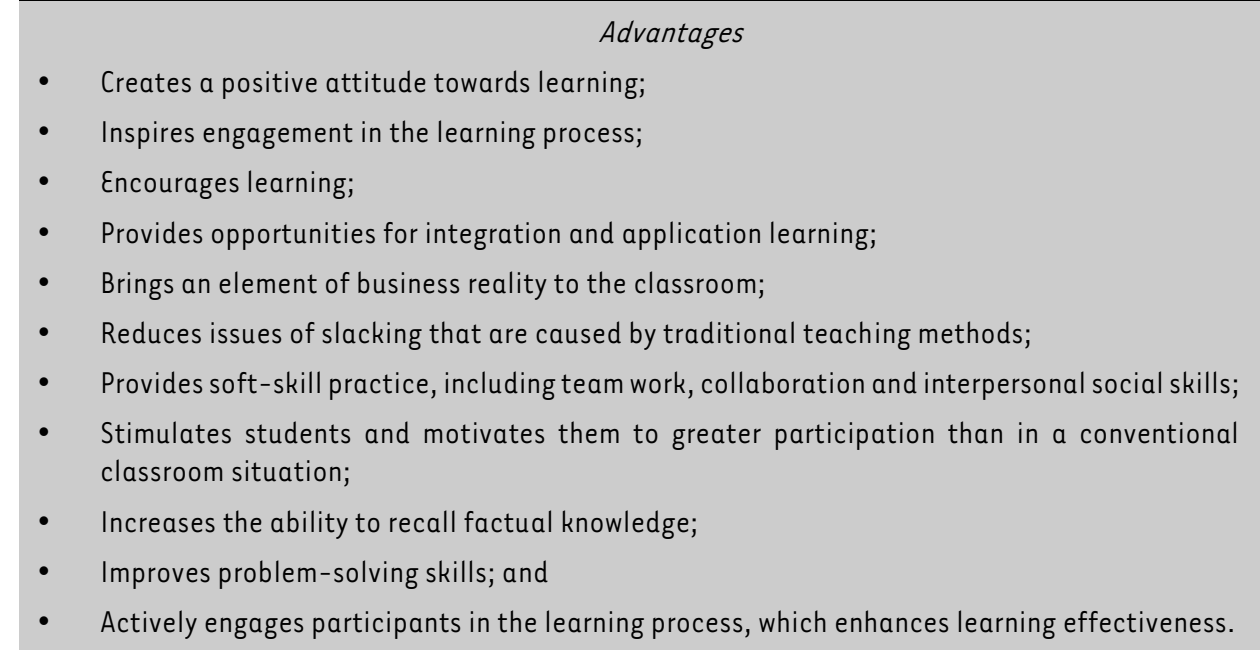

\section{Challenges}

- Time constraints;

- Possible student confusion about what is expected;

- Students become frustrated with technical difficulties inherent in the simulation; and

- Educators struggle to provide feedback and answer any questions if the simulation takes place outside of class time.

Source: Adapted from Fouché and Visser (2008:599); Giroux and Pasin (2011:1246); Hoffjan (2005:63); Knechel (1989:411-419)

Subsequent to the quantitative evaluation, focus group discussions were held to inform the quantitative findings, obtaining insight not only on why the participating students indicated the audit simulation enhanced their perceived broad competence, but also, to evaluate the use of simulations in the audit classroom further. The latter approach therefore ensured a triangulation of the results found for the entire project.

This study therefore hopes to contribute to audit education specifically, by reporting on students' views of the use of an updated (with the latest auditing standards and other legislation) audit simulation, retrieved through qualitative methods. The latter will add new knowledge to literature pertaining to the usefulness of simulations in accounting education, specifically due to the qualitative method followed in obtaining the data. The use of a qualitative research design also contributes to the richness of the data obtained. These contributions may also be of universal value as the use of simulations in accounting education has been advocated by local researchers as well as many abroad. The findings of this study are thus of value to the broader spectrum of accounting educationalists outside the South African context.

\section{RESEARCH DESIGN AND METHOD}

As noted earlier, a qualitative approach was followed in collecting the data for the present study. The sample population consisted of third-year audit students who had participated in the 
simulation of a chartered accountant programme at a SAICA-accredited South African university (hereafter referred to as University X). In obtaining the data qualitatively, several focus group discussions were held with the students who volunteered to participate in the discussion within one week after completing the audit simulation. The number of groups was determined by randomly selecting students from the volunteers to compile groups of between six and eight students, as suggested by Davies (2007:168-173), up until all students who volunteered had been divided into various groups. By doing so, eight focus group discussions were held, consisting of a variety of students in terms of their race, culture, gender and originating campus of University X. The author is of the opinion that adequate coverage was obtained by this means, as, according to Davies (2007:149), qualitative research ends when the themes emerging from the research start to repeat, i.e. when saturation is achieved. After the fifth focus group discussion was held, it was clear that the same matters were being raised by all the focus groups. Although it seemed as if saturation of the data was achieved after five focus group discussions, it was decided nevertheless to conduct the remaining three focus group discussions to ensure that all volunteering students were granted the opportunity to participate. The risk of biased results was therefore mitigated.

Each focus group was asked four open-ended questions. The focus groups thus followed an unstructured approach designed by the author to aid in fulfilling the research objectives. The first question asked was based on the results of the quantitative analysis, reported in a different study (De Villiers, 2015) and explained earlier, which indicated that the audit simulation enhanced the audit students' perceived broad competence significantly. The question was framed as follows:

- Why do you think the audit simulation assisted you to better comprehend the audit subject?

The second, third and fourth questions were aimed at assisting the author to further evaluate the audit simulation in order to obtain information on the students' use of simulations in the audit classroom. These questions were framed as follows:

- What went well during the audit simulation?

- What didn't you enjoy about the audit simulation?

- Do you have any other comments you would like to add?

The author formed part of each focus group and only facilitated the questions as students were allowed to generate their answers, ideas and any other valuable information obtained from the focus group discussions themselves.

After obtaining the permission of the students in each focus group, the discussions were voicerecorded and then independently transcribed. By utilising the software tool, ATLAS.ti, the transcripts were thoroughly content analysed after multiple readings of the transcripts to identify all the reasons and motivations (themes) students provided on why they think the audit simulation assisted them to better comprehend the audit subject. This was done by extracting all the quotes from the focus group transcripts for the first question and categorising each quote into a possible reason or motivation (theme). This approach was repeated in analysing the answers obtained for the remaining questions. Only themes that were evident across all the focus groups were retained after applying careful judgement. Any quotes extracted in Afrikaans were accurately translated into English. The author took great care in ensuring that the meaning intended by the Afrikaans students was not altered in any way by performing multiple readings of the Afrikaans quotes and only then translating them into English. This was done by comparing the 
translated quotes to the original Afrikaans quotes, thus ensuring an accurate translation of the Afrikaans quotes into English.

\section{FOCUS GROUP RESULTS}

The sections below provide a discussion of the themes that emerged from the first question posed to students, namely why they thought the audit simulation assisted them to better comprehend the audit subject. Some of the individual noteworthy quotes by the participants are also provided. The themes discussed next were identified on the basis of the content analysis performed. It should be noted that the themes are not discussed in any particular order and that some of the quotes are interrelated. Therefore, the results (themes) should be interpreted within this context.

\subsection{Holistic view of the audit process}

One of the most prominent reasons that emerged from the focus group discussions is that students felt the audit simulation gave them the opportunity to obtain a better understanding of the audit process as a whole as they reported being able to see how the theory of the various steps in the audit process came together. Some of the students' comments include:

I personally had a better understanding of how the whole audit process works. Before the audit simulation, you learn about pre-engagement activities and about the audit report at the end of the audit, but I did not really have an understanding of all that stuff together. So it helped me a lot.

I think what also helped is the fact that you could do the audit from the beginning to the end, as to where you had class you just did a fraction of the work at a time.

I think the more practical something is, the more easier it is for you to understand rather than the theory because the theory has a whole lot of scope that you need to cover but when you see it and you get to follow it through the whole process, you get to see oh, this is what it actually means.

It helps you to visualise the whole thing from beginning to end and not just the theoretical aspects we learn.

I think that the simulation - uhm - put the pieces of the puzzle together in terms of the whole how each section is linked to another.

\subsection{Sufficient communication}

The students indicated that the use of Facebook, the platform used for communication during the audit simulation, assisted in their learning process as it was a useful method of communication between themselves and the lecturer because they could see other students' questions and the answers provided. The students stated the following:

You do not actually realise how many of these groups actually have the same question. It was really interesting to me to see, for example, when we sat and wondered about one thing, and two days later, a different group asked the same question and then you answered it on the Facebook page.

Everybody could see what the answer is to the questions posted; I really liked it and I was on that page regularly. 
It also served as auseful method of communication outside the audit classroom:

For me it was a great source of communication because when I wanted to know about something, I did not have to send an email to hear about it, because I will first look if someone else has not already asked. And then it makes it easier than sending unnecessary emails.

\subsection{Active involvement in the learning process}

The simulation proved to be a tool that actively involved the students in the learning process, which, in turn, assisted them to see how an audit is actually performed and how the theory should be applied in an actual scenario. This was made evident through comments such as:

I think it's how the audit procedures actually begins, as vacation work also helped but here you could have seen better how it was actually going to be applied, and not just rote learn it.

I think the planning part of the audit was pretty cool to like see all the theory that we have already done, and how the whole planning process fits together by doing it step by step. It helps you to see what auditors really do.

It's one thing to learn theory from a textbook, but it's another thing to see how you should take the information given to you and complete a working paper that should form part of the audit in total.

It further enhanced the students' understanding and memory-retention ability:

Okay, I think overall, just the whole practical aspect of the whole thing, as we are currently only just learning theory, theory, theory, but now we all basically know how it is practically applied and this helps a lot. I learn when I do something practically; I remember it more easily than just learning the theory.

See, for me it was great. I got the creditors section and I really now know and understand the whole creditors process and where everything fits in.

I think with the working papers - it would be easier to remember something, or click a certain topic - you'll actually click better 'cause you'll literally see what the working papers looks like and you'll easier remember what is on that working paper, which kind of flows back to the theory that you studied.

I have to say, just to put everything in perspective - it helped me a lot - it's not that I am ready to go to a company and audit it now, but it helped me to have a better understanding of everything. I think in future papers if you get a question where you are not sure what the answer is, it will be easier to rationalise the issue and come up with an answer, even if you have to thumb suck it.

\subsection{Working as part of a group}

The fact that the students were required to work in groups proved to be a useful method of teaching that helped in their learning. The students noted that if they did not understand something, their peers were there to assist them and vice versa, for example:

The team work really worked well for me. If you did not know something, you just said, come and help here quick, and then when they did not know something, you go and help them. 
If one person struggled with something, another person immediately helped that person. Although you had certain tasks allocated to you, when you struggled someone was there to quickly assist you. It was nice to see how we can help each other.

Their peers explained at a more understandable level and from a different perspective:

To hear how someone else thinks about something, I really think helped me.

To discuss in the group made more sense than a lecturer trying to explain it to you where students in the same position as you - you ask them a question 'cause you're not sure, then the whole group starts talking about it. They understand what your question is, more so than the lecturers. So they explain it to you on your level so that you understand it better than sitting in class answering a question - it's a textbook answer, where a student knows what the textbook answer is, but they see it this way and maybe you understand it better.

When you sometimes do not understand something or when the lecturer explains something that you do not click, but the person next to you understands it, you can just say, quickly explain this to me, then the person says ok, because he understands it and explains it, I can almost say, at a student level which makes more sense.

\subsection{Visualising the theory in practice}

The use of actual visual aids such as actual audit working papers and engagement letters gave students the opportunity to see how audit theory is applied in practice and also made the work more interesting and understandable. This proved to have contributed to the students' enhanced perceived competence in the audit subject, as was made evident in the following statements:

I completed the engagement letter, and to see the physical thing, who should sign, who is responsible for what and what the content requirements of an engagement letter are, really helped. It is something we do in class but we do not actually understand it.

For me it was the second section of the audit simulation. In section $C$ and $D$ you physically saw how to complete a working paper. I had to do a graph, so every time I completed a field, I saw how the graph developed. I really enjoyed it.

It helped in the sense of the practical part of auditing, since auditing was for the past two years for myself, it's been based on theory, theory, theory, you understand the theory, theory, theory but they weren't showing how to apply the theory, so having the simulation actually gave us a better understanding ... especially when it comes to audit procedures because we understand that you have to confirm, you have to inspect, you have to observe, but then now that we actually have a better understanding as to what these documents actually look like and what we're supposed to look out for - actually helped us to have a better understanding.

The use of the videos to simulate the stock count also proved to have given students some feel of the audit reality and to better understand the audit subject. One student commented:

I feel that it gives you a perspective of audit practice especially with auditing inventory. 


\subsection{Effective and sufficient feedback}

Some students noted that the feedback obtained from the simulation assisted them to see what they did not understand correctly during the simulation, and how it should have been done. One student noted the following:

The feedback was not as theoretical as a memo discussion of a class test would be. It was not just about this is where you did not understand the theory correctly, it was much more practical and you could make the link much quicker and it made sense afterwards.

Like the feedback session was quite long - you explained topics like from the start till the end and I feel like in that five minutes that we had this done, I think we learnt so much that whatever we didn't understand.

\subsection{Replicated audit practice}

The fact that the audit simulation replicated audit practice offered students the opportunity to be part of a real audit experience and to obtain a better understanding of how the auditing theory is applied in practice. Some of the quotes include:

In practice it may not be so easy, but it gives you an idea of how it will be as you must actually perform the tests.

Yes, I actually did not have a clue. I studied the theory but did not actually have an idea what's going on. When it came to the review of the things it was like you do the work from the beginning and it helped me to understand.

I think, throughout this whole thing, you saw how it's going to work in practice. You are going to work under pressure, you are going to work with people you do not know, you will have to do other people's work, you will have to do extra, those types of things. So I really think you now saw how it is going to be and if you are going to like it or not.

I've never seen how working papers look like. That was the first time for me, so actually, how the theory would actually be put into real practice and real life, like how the - how a pre-engagement really looks like, how an audit - those audit procedures - how you actually put them on working papers.

\subsection{Working with a diverse group of individuals}

The fact that the groups consisted of diverse individuals from different biographical backgrounds, cognitive strengths and commitment levels to their studies, also assisted the students in various ways. The following quotes point to this:

Due to the fact that we were a quite diverse group, you realised that you have to apply different methods of getting people involved or that you have to treat them differently to get them to participate. I do not say that you have to change your style, but that you need to realise that everybody is not that committed to their studies as you are, but you need to get them to take responsibility of their work.

You need to be adaptable and you need to show understanding for different people's abilities. 
Yes, to sometimes just step back and think, okay, how does this person see it, and then maybe adjust your method of thinking.

Yeah, I think also when you're selecting groups. When I'm with my, let me say English speaking or Tswana speaking people and then we have to accommodate somebody who is English speaking.

I come from a place where there is still a lot of racial separation and now I have to work with people from different races for the first time in my life. It showed me that they know just as much as we do, it's not about this or that, but I am being completely honest here, it opened my eyes.

\subsection{Opportunity to develop various soft skills}

The most salient aspect that students reported was that the audit simulation really helped them to develop several soft skills. Firstly, the students mentioned that the audit simulation enhanced their communication and language proficiency skills and helped them to develop more selfconfidence. Some students stated the following:

It helped me to be able to communicate with people I did not know.

There was this one girl in our group that was very shy, we encouraged her by asking her a lot of questions and by boosting her to be part of the group and to speak to us. I think it helped her to develop more self-confidence to speak in front of people.

I think it helped me to be more comfortable to give my opinion, and to say to everybody, okay, I think we are doing this wrong and that we should rather do it this way, in contrast to just sitting there and to accept what everybody else says.

My English improved a lot.

In my opinion, the fact that it was in English was a very good thing. I think English dominates the work force and therefore I think it's actually fantastic exposure.

The development of time management skills was also evident:

Time management, as we all did not always have the same time gaps. Our group was fortunate enough not to have a lot of issues with this, but it was still something we had to consider.

It learned me to compromise because we plan now, okay, we have an hour break between these classes, but now it does not fit everybody, now you have to shift some things around as to accommodate everybody.

I think it helped me to plan better strategically, not just because we had all our other subjects still, but also because we had ten weeks. So, actually it had an element of time management and it helped me with this.

At the beginning I was very scared. I did not know how I was going to get everything done, but this is how you learn to manage your time.

Yes, I think it forces you to stick to your time planning, especially because you work in such large groups. If you do not make the deadlines, things can go wrong very quickly and you can keep the other people in the group waiting. This forces you to stick to your deadlines.

Some leadership skills were also improved: 
I think the group leaders learnt a lot from this. You had to take charge and help everybody.

I feel that it taught me to just begin, to lead people and to say, okay, you do this and you do this. I feel that it helps you to be able to lead.

It also developed logical thinking and problem-solving skills, for example:

You must be able to think logically. You must be able to think, okay, if something goes wrong now, what you are going to do.

As noted earlier, the second, third and fourth questions were aimed at assisting the author to further evaluate the audit simulation by obtaining information on how the students felt about the use of simulations in the audit classroom. The results showed the following:

\subsection{The use of social media platforms such as Facebook}

The students indicated that the incorporation of Facebook into the audit simulation created a positive attitude within the groups and also motivated them to learn. This was made evident by student quotes such as:

Our group loved using Facebook. We were like one of the first groups that uploaded photos onto the Facebook page, and we also uploaded a video. Our group where there hey.

It was a very good idea. It's well executed. I'm very glad that it worked because I mean, sometimes, then you have a question, then you're there, and I mean, you know, it's technical points, so it's not like you can ask friends.

\subsection{Well-structured and -developed simulation}

The way in which the simulation was structured (built) and developed (i.e. the framework applied) appeared to contribute to the positive experience reported by the students. The students stated that:

I think the participant guide explained it and laid the audit process out better. It showed us why we do what we do and what you should do and know at each step in the audit process.

I really liked it. I think a lot of time and effort went into it.

The structuring made it easy to navigate through the simulation.

If you had to go and look for something you immediately knew where to go and look.

It was very well developed.

The reference on the working papers made it easy to relate where to find stuff. You do not have to search for two hours on end to get the stuff. So I think the references really worked well. 


\subsection{Working in audit teams}

The students indicated that the random assignment of students into the various groups initially may have been received negatively, but they later reported this as a positive thing as they made new friends through this arrangement. For example:

Because we were not allowed to choose our own teams you met new people. Like now, everybody greets each other.

I enjoyed it, I made new friends.

This assignment came with a lot of other assignments where we were allowed to choose our own groups and we were usually only three people that knew each other. Now, suddenly you have to be groups of ten people, it's awkward. So now that you have assigned us to a group already, we know okay, we had to meet new people and that was good for me.

We were a great group, and in the end I was glad that the groups were structured in this manner. It is so that we met new people in the process, people that have been studying with you for three years and you do not actually know the person. I think it opens other doors and new friendships.

The students also indicated the following as factors (themes) that could have brought even greater improvement to their experience, flagging these as issues to be addressed in future usage of audit simulations:

\subsection{Timing of performing the simulation}

The one major issue that students raised is the fact that the simulation was performed at a time in their studies when they were extremely busy and that this had placed a great deal of pressure on them. This was apparent in quotes such as the following:

This semester you have a lot of assignments, I mean the strategy assignment is a big project and you have to drive back and forth. You also have a financial management, accounting and tax assignment and then audit also comes along. I think that we need to get a better time for this.

During the second semester, it feels that the lecturers for some reason have ten million things that they try to finish in a month or a month and a half. Everybody has assignments, everybody has whatever, which they try to finish during that time and during the first semester, which is actually the long semester, everybody is like chilled.

\subsection{Cost versus benefit}

The students felt that the simulation had some unexpected financial implications and the fact that the project only counted towards $10 \%$ of their final mark was deemed by them not to be worth the financial cost of submitting the project in hard copy. Some students felt strongly about this issue, as stated below:

To go and print everything was a mission and a big unexpected expense.

It is quite a bit of paper work, a lot of things to print. Can't we rather have submitted it electronically? 
I did not like the fact that it counted so little for so much work, like only $10 \%$ of our mark. Like some of us did not even need that $10 \%$ and then you had to neglect your other subjects for it.

\section{DISCUSSION}

The results of the qualitative analysis confirmed the results of various researchers in the field of accounting education and education in general. It also highlighted the invaluable contribution that the use of more active learning tools, such as the simulation evaluated in this study, may make to the learning experience of students.

From the focus groups it was noted that the audit simulation gave students the opportunity to obtain a better understanding of the audit process as a whole and to see how the theory of the various steps of the audit process fit together. The simulation therefore proved to be a tool for addressing the issue of students lacking an all-inclusive view of the audit process, argued by researchers such as Barac (2012:48) and Helliar, Monk and Stevenson (2006:6) to be one of the biggest issues in audit education.

The fact that the students felt the use of a social media platform (i.e. Facebook) assisted in their learning process concurs with the findings of Bosch (2009:185), as well as Barnes, Marateo and Ferris (2007), who highlighted some advantages of using Facebook as a communication medium between lecturers and students. These included that the lecturer is able to answer the same question, in bulk, for a large number of students and that the use of social media is a useful and fresh approach to communication at higher education level (Barnes et al., 2007; Bosch, 2009:185). The latter finding also proves that one of the earlier mentioned challenges of using simulations, i.e. educators struggling to provide feedback and answer questions when simulations take place outside of class time, can be mitigated by the use of social media as a tool of communication between the students and the lecturer outside the classroom.

Furthermore, the fact that the students felt that they were actively involved in the learning process supports the findings of Cox, Shah and Zdanowicz (2013:651), Everly (2013:151), Lubwama, Satin and Tan (2013:400), as well as Steenkamp and Von Wielligh (2011:18), who concluded that the use of this method contributes significantly to the learning experience of students and their ability to grasp important concepts. Moreover, statements made, such as that working as part of a group assisted students in their learning, support the arguments for cooperative learning techniques in the classroom environment by researchers such as Brown, Callahan, Harder, Orlich and Trevisan (2010:271) and Nitkin (2011:132).

Arguments put forward by researchers such as Moore and Scevak (1997:205) and Schmidt (2009:68) concerning the advantages of using visual aids in teaching were further supported by the findings of the present study as students were able to visualise the theory in practice, which, in turn, made it interesting and understandable.

Some of the conclusions concerning the advantages to learning brought by sufficient and effective feedback, as noted by Gawe, Jacobs and Vakalisa (2012:283), as well as Moore (2012:235), are supported by the findings of this study. This was made evident through students indicating that the feedback obtained as part of the simulation process assisted them to identify any misconceptions they had during the simulation and how it should have been performed. This feedback therefore guided improvement and helped students to firstly identify difficulties, and secondly, gave them the opportunity to correct their errors. 
Because the students felt that the simulation replicated audit practice, and, in turn, offered them the opportunity to be part of a real audit experience and gain a deeper understanding of how auditing theory is applied in practice, the usefulness of altering the audit classroom to represent the actual audit environment that students will form part of in practice, is obvious. These findings are in line with the conclusions reached by researchers such as Fouché and Visser (2008:599), Giroux and Pasin (2011:1246), Hoffjan (2005:63), as well as Knechel (1989:411-419), who claimed that lecturers in the accounting education field should attempt to alter their classroom setting by implementing more experiential learning techniques such as, but not limited to, simulations and games that would result in practice being imitated in the classroom.

It was also noted from these focus group results that the following advantages of using simulations as a teaching tool, as noted earlier, were brought to the audit classroom:

- Inspired engagement in the learning process;

- Encouraged learning;

- Opportunities for integration and application learning;

- An element of business reality in the classroom;

- Soft-skill practice that included leadership, team work, collaboration, time management and interpersonal social skills;

- Increased ability to recall factual knowledge;

- Improved problem-solving skills; and

- Actively engaged participants in the learning process, which enhanced learning effectiveness.

The results of the study have also shown that the challenges of simulation use can be mitigated, as the simulation proved to be an instrument that caused minimal confusion and frustration, if any, to students. The issue that simulations are time consuming proved to be an on-going concern, although from the findings of this study it seems that this issue did not detract from the students' reported learning experience.

Having said this, it was noted that certain factors of the simulation, if altered, may improve students' experience of simulations such as this one, as the students indicated that:

- The project was very time consuming and was applied during a very busy period during their final study year (timing). Although it was said to be time consuming, the empirical findings revealed that participants' time management skills were developed in the process and therefore a positive effect was exercised on their learning; and

- The simulation held unexpected financial costs for participants due to the required submission of a hard copy audit file. Students felt that this cost was not proportionate to the small percentage that these few marks counted towards their final mark for the audit subject (cost versus benefit).

\section{RECOMMENDATIONS}

From the preceding discussion it is clear that this study concurred with the findings of various researchers in this field of enquiry. Based on these findings it is recommended that audit lecturers should: 
- Attempt to make use of simulations such as the one evaluated in this study to ensure that students obtain a holistic view of the audit process;

- Attempt to make use of social media platforms as a mode of communication between themselves and their students as this evidently has its advantages. It may also serve as a motivational tool, as noted from the students' responses, on what went well during the audit simulation;

- Make use of more active learning tools, such as simulations, to ensure that students are involved in the learning process and to provide them with the opportunity to apply their theoretical knowledge in actual situations;

- Increase the use of group work, in the audit subject specifically, as it proved to be useful in assisting student learning and in the overall learning experience of students. This is because working in groups provided the students with the opportunity not only to get assistance more easily, but it also enabled them to make new friends and interact with their peers;

- Attempt to make use of actual audit documentation, such as working papers, in explaining the concepts of auditing to students. Other subjects in the accounting profession may also possibly derive benefit from using physical visual aids in the teaching of the principles of the respective fields of specialisation;

- Attempt to provide students with more feedback on their performance regularly. This may assist them to identify issues in their learning upfront and provide them with the opportunity to obtain assistance at an early stage in the learning process. This in turn could result in improved marks and a better overall understanding of the subject matter in question;

- Attempt to change their classroom environment to replicate audit practice by using simulations and games that grant students the opportunity to gain exposure to the actual audit environment before they graduate;

- When planning to introduce this and other simulations in future, ensure that students have enough time to complete the simulation by introducing it during a less busy period of the year. However, it should still provide the opportunity to develop time management skills; and

- Revisit the cost versus benefit of performing the simulation to the students and maybe consider submitting the completed simulation electronically as opposed to hard copy, and to make it contribute towards a greater proportion of the students' final mark.

\section{CONCLUSION}

The objective of this study was to obtain students' views on the usefulness of simulations in the audit subject specifically, by following a qualitative approach in collecting data from students. The argument that qualitative approaches to data collection generate richer results has proven to be true, as valuable insights were obtained on how students perceived the use of simulations and the value it adds to their learning experience.

Based on the findings of this study, it can be concluded that audit lecturers should attempt to apply a teaching methodology that is student-oriented as well as lecturer-centred. By practising as such, it will enhance not only the quality of the student graduating from higher education, but will also ensure that lecturers strive to add value not only to the students' education, but also to the lecturers' personal and professional development, which, in turn, implies that accounting education is continuously transformed and remains up to date with the requirements of the diverse and unique population of students and public practice. 


\section{LIMITATIONS OF THE STUDY}

Although this study has demonstrated the value of using more active learning tools such as simulations as teaching instruments in accounting and specifically audit education, the results may be limited with regard to their generalisability as focus group discussions were confined to only one university in South Africa. Despite this fact, the investigation yielded valuable insights into the usefulness of simulations in audit education specifically. Bias was also restricted as all the students who participated in the simulation were invited to join in the focus group discussions. It should also be noted that it can never be certain that the content analysis performed on the transcripts would yield exactly the same themes if performed by someone else, due to the judgemental nature of transcript content analysis. However, the author took great care in ensuring that the themes identified were as precise and complete as possible. This was done by:

- Utilising the software tool ATLAS.ti to content analyse the descriptive data;

- Attentively reading the transcripts several times; and

- Applying careful judgement and precision when the final themes were compiled and when the quotes were extracted and translated.

Finally, it is recognised that the first questions posed at the students could be leading, and that the focus group could have included students that did not feel that the simulation assisted them to better comprehend the audit subject. Noting this limitation, the authors attempted to minimise this effect by including the last question that gave students the opportunity to state any other comments that they may have.

\section{AREAS FOR FURTHER RESEARCH}

Based on the findings of the study, the following possible areas for further research were identified:

- Expanding the study to all SAICA-accredited universities so as to corroborate or disprove the findings of this study lending itself to start forming a theory on the best approaches for the teaching of auditing at higher education level; and

- The effect of the newly developed audit simulation on students' auditing marks could also be tested as to demonstrate the actual academic benefit derived from completing simulations in accounting education.

\section{LIST OF REFERENCES}

Bagley, P.L. \& Harp, N.L. (2012). Shoe Zoo, Inc.: A practice in electronic work papers, tick mark preparation, and client communication through the audit of property, plant and equipment. Issues in Accounting Education, 27(4), pp. 1131-1151.

Barac, K. (2012). Learning approaches to the study of auditing followed by prospective South African chartered accountants. Southern African Business Review, 16(2), pp. 47-68.

Barnes, K., Marateo, R. \& Ferris, S. (2007). Teaching and learning with the net generation. Innovate, 3(4), pp. 1-8. Retrieved from http://www.innovateonline. net Date of access: 5 July 2014. 
Bosch, T.E. (2009). Using online social networking for teaching and learning: Facebook use at the University of Cape Town. Communication: South African Journal for Communication Theory and Research, 35(2), pp. 185-200.

Botha, N. (2014). Measuring Student Perceptions About the Use of a Computer Programme as a Teaching Aid in Auditing. Potchefstroom: North-West University. (MSc dissertation).

Brown, A.H., Callahan, R.C., Harder, R.J., Orlich, D.C. \& Trevisan, M.S. (2010). Teaching Strategies: A Guide to Effective Instruction, $9^{\text {th }}$ edition. Boston: Wadsworth Cengage Learning.

Cox, A.G., Shah, S. \& Zdanowicz, M.M. (2013). Student perceptions of the use of pre-recorded lecture modules and class exercises in a molecular biology course. Currents in Pharmacy Teaching and Learning, 5, pp. 651-658.

Davies, M.B. (2007). Doing a Successful Research Project Using Qualitative or Quantitative Methods. New York: Palgrave Macmillan.

DeCoster, D. \& Prater, G. (1973). An experimental study of the use of a business game in elementary accounting. Accounting Review, 48(1), pp. 137-142.

De Villiers, R.R. (2015). Evaluating the effectiveness of a newly developed audit simulation in improving the perceived broad competence of audit students. The Southern African Journal of Accountability and Auditing Research (Unpublished).

Everly, M.C. (2013). Are students' impressions of improved learning through active learning methods reflected by improved test scores? Nurse Education Today, 33, pp. 148-151.

Fouché, J.P. (2006). Program Development for First Year Accounting in South African Higher Education. Potchefstroom: North-West University. (PhD thesis).

Fouché, J.P. \& Visser, S.S. (2008). An evaluation of the integration of a board game in introductory accounting. South African Journal of Higher Education, 22(3), pp. 588-601.

Fowler, L. (2005). Active Learning: An empirical study of the use of simulation games in the introductory financial accounting class, Allied Academies International Conference, October, Las Vegas, Nevada.

Gawe, N., Jacobs, M. \& Vakalisa, N.C.G. (2012). Teaching Learning Dynamics, $4^{\text {th }}$ edition. Cape Town: Pearson.

Giroux, H. \& Pasin, F. (2011). The impact of a simulation game on operations management education. Computers \& Education, 57, pp. 1240-1254.

Gurau, C., Loukis, E., Ranchhod, A. \& Trivedi, R. (2013). Evaluating the educational effectiveness of simulation games: A value generation model. Information Sciences, 264, pp. 76-90.

Helliar, C.V., Monk, E.A. \& Stevenson, L.A. (2006). The skill-set of trainee auditors, National Auditing Conference, March, University of Manchester, Manchester.

Hoffjan, A. (2005). Calvados: A business game for your cost accounting course. Issues in Accounting Education, 20(1), pp. 63-80.

Knechel, W.R. (1989). Using a business simulation game as a substitute for a practice set. Issues in Accounting Education, 4(2), pp. 411-424.

Lubwama, C.W.K., Satin, D.C. \& Tan, J. (2013). A real-world business approach to teaching MBA managerial accounting: Motivation, design and implementation. Issues in Accounting Education, 28(2), pp. 375-402. 
Mensching, J., Adams S.J., Gardiner, L. \& Jones, N. (2012). Modeling the budgeting process: Enriching the learning environment using Monte Carlo Solutions. AlS Aducator Journal, 7(1), pp. 53-67.

Miller, C.R. \& Savage, A. (2009). Vouch and trace: A revue recognition audit simulation. Issues in Accounting Education, 24(1), pp. 93-103.

Moore, K.D. (2012). Effective Instructional Strategies: From Theory to Practice. London: Sage.

Moore, P.J. \& Scevak, J.J. (1997). Learning from texts and visual aids: A developmental perspective. Journal of Research in Reading, 20(3), pp. 205-223.

Nitkin, M.R. (2011). "Game of Business" a game for use in introductory accounting. Accounting Educators Journals, 21, pp. 131-152.

Schmidt, S.J. (2009). Development and use of visual explanations: Harnessing the power of the "seeing" brain to enhance student learning. Journal of Food Science Education, 8, pp. 68-72.

Steenkamp, L.P. \& Rudman, R.J. (2007). South African students' perceptions of the usefulness of an audit simulation. Meditari Accountancy Research, 15(2), pp. 3-41.

Steenkamp, L.P. \& Von Wielligh, S.P.J. (2011). The perceptions of accounting students of the usefulness of an audit simulation at university level. Southern African Journal of Accountability and Auditing Research, 11, pp. 9-21. 